\title{
SPECIES-SPECIFIC SEED VIGOR TEST OF AGING CHIVE FOR RESTORATION AND REGIONAL ADAPTATION UNDER CLIMATE CHANGE
}

\author{
NA, C. S. ${ }^{\#-B A E K, ~ S . ~ G . ~}{ }^{\#}$ - YANG, S. Y. - PARK, C. Y. - KiM, J. H. - LEE, M. H. - PARK, Y. S. \\ Seed Conservation Research Division, Baekdudaegan National Arboretum, Bonghwa 36209, \\ Republic of Korea \\ ${ }^{\#}$ These authors contributed equally to this work \\ *Corresponding author \\ e-mail: yspark1219@bdna.or.kr; phone: +82-54-679-0621; fax: +82-54-679-0626
}

(Received 30 $0^{\text {th }}$ May 2019; accepted $16^{\text {th }}$ Oct 2019)

\begin{abstract}
This study aimed to develop a vigor test method that can be applied in the seed storage and ecological restoration of Aging chive (Allium senescens L). The impact weight of each temperature on germination was described with a sine curve equation. The closer the temperature was to $18.9^{\circ} \mathrm{C}$, the faster the germination was, and temperatures below $8.0^{\circ} \mathrm{C}$ and above $29.7^{\circ} \mathrm{C}$ negated the temperature accumulation effect. A verification and validation test confirmed the 'impact weight on germination' to be reasonable because it exhibited a hump-shaped relationship with the time to reach $85 \%$ germination among the temperature treatments. Furthermore, the time to reach 25,50 and $75 \%$ germination and the change in germination with time did not differ between the actual and predicted values. The hourly accumulated value of 'impact weight on germination' was taken as the temperature score (TS), and the temperature requirement for vigorous germination was 294TS. The temperature requirement was applied to hourly temperature data from Geumsan, Korea, from 1999-2018, and the average date of vigorous seed germination was May 3. Increasing temperature elevation advanced the predicted germination date. Based on the earliest predicted date, germination will advance rapidly. If the temperature is elevated by $2.5^{\circ} \mathrm{C}$, the germination date will advance markedly to November 23 .
\end{abstract}

Keywords: Allium senescens L., German garlic, germination, seed vault, wild plant

\section{Introduction}

The Baekdudaegan Global Seed Vault (BGSV) of the National Baekdudaegan Arboretum was established to preserve and safely store seeds of wild plants collected worldwide. A seed vault is a center for permanent storage, in contrast to a seed bank, which allows seeds to be deposited and removed easily. The permanent storage of seeds conserves biodiversity and allows restoration to prevent extinction, which could occur in response to climate change and natural disasters, among other events. Because seeds are the core of ecological restoration (Broadhurst et al., 2015), the BGSV could serve as a potential material supplier for a wide range of species restoration and ecosystem reconstruction activities as it includes seeds from wild plant species.

Seed viability is one of the most important factors for the permanent storage of seeds and ecological restoration (Marcos-Filho, 2015). Storing seeds confirmed to have high vitality by a vigor test not only increases their storability but also affects the efficiency of the seed vault. Moreover, a vigor test provides information that can be used to restore the germination of seeds stabilized for storage, which is a key factor in the restoration of natural habitats (van der Valk et al., 1999). 
To achieve ecological restoration using seeds, information on germination characteristics and the environment of the target site should be taken into account. Since the selection of species for restoration gives priority to native species, vigor test results for the species and environmental information at the target site are especially important for determining the success or failure of the restoration.

The species used in this study, Aging chive (Allium senescens L.), is a perennial herb of the Liliaceae family with thicker leaves than other members of this family (Oh et al., 2012). Because of its very strong scent, its aromatic components and chemical composition have been studied (Chung and Lee, 2001; Chung, 2010). For example, methanol extracts of this species were found to suppress reactive oxygen species (ROS) production and lipid accumulation and consequently inhibit adipogenesis (Choi and Kim, 2014). Despite the studies on this species, it is classified as a rare plant in Korea and is in danger of extinction (Korea National Arboretum, 1997).

Thus, this study aimed to develop a vigor test method for A. senescens, an endangered species, that can be flexibly applied during seed storage and ecological restoration. Furthermore, germination timing was inferred using temporal temperature data from seed collection sites, and the variability of this trait in response to climate change was predicted. We intend to incorporate these results into the BGSV database (DB) of wild species seeds.

\section{Materials and methods}

\section{Seed information and experimental conditions}

Seeds of $A$. senescens collected from the Chungcheongnam-do Forest Environment Research Institute, Korea, in 2018 were used in this study (N36.4336, E127.3721). The collected seeds were stored at $-20^{\circ} \mathrm{C}$ before the experiment started. Nonempty and healthy seeds were selected for experiments using a soft X-ray test (EMT-F70, Softex Co., Ltd, Japan). The seed germination rate was measured using a thermal gradient plate (TGP, ONSOL Corp., Suwon, Korea). The TGP consisted of 60 compartments with individually controlled day and night temperature conditions. The day and night lengths were both fixed at $12 \mathrm{~h}$. The day and night temperatures included 10- and 6-step gradational conditions with $3{ }^{\circ} \mathrm{C}$ intervals from 7 to $34{ }^{\circ} \mathrm{C}$ and $6{ }^{\circ} \mathrm{C}$ intervals from 5 to $35^{\circ} \mathrm{C}$, respectively. In total, 60 temperature combinations were implemented. The germination rate was observed until 22 days after sowing (DAS) (3 weeks). Over 40 seeds and 4 repeats were allocated per temperature condition, including temperatures below the experimental conditions for verification and validation.

\section{Species-specific seed vigor test}

Temperature data measured every hour were used in this study. Therefore, the day and night temperatures of each temperature condition were accumulated for $12 \mathrm{~h}$ per day. In the first step of the species-specific seed vigor test (SSVT), the effect of day and night temperatures on seed germination was evaluated by two-way analysis of variance (ANOVA). In the second step, the relationships between temperature and the germination rate were analyzed. Temperatures affecting or not affecting germination were distinguished by correlation analysis between the germination rate and cumulative hours at each temperature, and the directions of their effects, i.e., whether they were positive or negative, were investigated. In addition, to examine the effects of temperature on germination, the 
standardized regression coefficient of each temperature condition was obtained by multiple linear regression analysis. In the third step of the SSVT, the cumulative score was calculated for each temperature. The largest standardized regression coefficient obtained in the previous step was set to 1 , and the remaining values were converted into the ratios of the largest value. Therefore, the standardized regression coefficients, namely, the relative weights of the cumulative temperature effects on germination, were converted to a range with a maximum of 1 . Nonlinear regression analysis was performed with the converted values, and the simplest equation, specifically, the one with statistical significance and an $\mathrm{R}^{2}$ value greater than 0.9 , was selected. The simplest form was selected for addition to the DB of seed vaults and seed banks. In the last (fourth) step, the temperature requirement for vigorous germination of $A$. senescens seeds was evaluated as the cumulative temperature score (TS) defined by the selected equation when the germination rate reached $85 \%$. A germination rate of $85 \%$ is the standard rate used to evaluate seed vitality, as suggested by the Royal Botanic Gardens, Kew (Newton et al., 2009).

\section{Verification and validation of the SSVT}

For verification and validation of the SSVT, we simplified the temperature conditions irrespective of day or night. All compartments of the TGP were set at $20^{\circ} \mathrm{C}$ until the first three DAS. Then, 7 gradational temperatures separated by $5{ }^{\circ} \mathrm{C}$ intervals from 5 to $35^{\circ} \mathrm{C}$ were applied in accordance with each treatment. After 9 DAS, the temperature of all treatments was reset at $20^{\circ} \mathrm{C}$. Therefore, the temperature sets supplied to each treatment until 3 DAS, during 3-9 DAS and after 9 DAS were 20-5-20, 20-10-20, 20-15-20, 20-20-20, 20-25-20, 20-30-20 and 20-35-20 ${ }^{\circ} \mathrm{C}$. These temperature sets were used to test the canceling effects of temperature accumulation and impact weight ratios on germination.

Verification and validation were performed from two main viewpoints. The first viewpoint was the property of 'impact weight on germination' being given to each temperature. To this end, the time it took to reach an $85 \%$ germination rate was compared with the 'impact weight on germination'. The second was the accuracy of this property in predicting the temperature requirement of A. senescens. To this end, differences between the actual and predicted times required to reach germination rates of 25,50 and $75 \%$ were evaluated. In addition, the predicted germination rates were compared with the actual values according to the elapsed time.

\section{Regional temperature data and simulation of climate change}

Hourly temperature data of the sampling area were collected. According to the Korea Biodiversity Information System (Korea National Arboretum, 2019), seeds of $A$. senescens are generally sown in late October and germinate in the spring of the following year. Thus, in this study, it was assumed that the seeds were sown in late October, and the temperature accumulation started on November 1. The temperature accumulation pattern was investigated by applying the equation developed as part of the SSVT to the hourly temperature data from 1999 to 2018 in Geumsan, Korea (N36.1056, E127.4817; Altitude $173 \mathrm{~m}$ ). In addition, the time required to achieve vigorous seed germination was considered the time when the temperature requirement of A. senescens was fulfilled. To simulate climate change, the elevated temperature method applied by Park et al. (2018) was used. Temperature increases of 0.5 to $6.0^{\circ} \mathrm{C}$ with a $0.5^{\circ} \mathrm{C}$ interval were applied to the temperature data from 1999 to 2018. 


\section{Statistical analysis}

For statistical analyses, SPSS 21 (SPSS Inc., Chicago, IL, USA) and the 'fRegression' package of the R program were used.

\section{Results}

\section{Species-specific seed vigor test}

In the first step of the SSVT, the effects of day and night temperatures on the germination rate were investigated by two-way ANOVA (Table 1). The germination rates were not influenced by day temperature, night temperature or their combination until 3 DAS because they remained at $0 \%$ during that period. In contrast, day temperature, night temperature and their combination began to elicit changes in germination rates 6 DAS. Thus, since the supplied temperatures affected the germination rate, regardless of whether they were supplied during day or night, the following steps of the SSVT focused on temperature itself without the separation of day and night.

Table 1. The p-values obtained from two-way ANOVA of the effects of day and night temperatures on the germination rate. The durations of both day and night were $12 \mathrm{~h}$

\begin{tabular}{c|c|c|c|c}
\hline \multirow{2}{*}{ Days after sowing } & \multicolumn{3}{|c|}{ Temperature } & \multirow{2}{*}{ N } \\
\cline { 2 - 4 } 3 & Day & Night & Day * Night & \\
\hline 3 & - & - & - & 480 \\
6 & 0.000 & 0.000 & 0.000 & 480 \\
9 & 0.000 & 0.000 & 0.000 & 480 \\
12 & 0.000 & 0.000 & 0.000 & 480 \\
15 & 0.000 & 0.000 & 0.000 & 480 \\
19 & 0.000 & 0.000 & 0.000 & 480 \\
22 & 0.000 & 0.000 & 0.000 & 480 \\
\hline
\end{tabular}

In the second step, the relationship between the germination rate and temperature was investigated. In the correlation analysis results (Table 2), $29{ }^{\circ} \mathrm{C}$ was not related to the germination rate, but the remaining temperatures had an effect on the germination rate. Temperatures in the range of $10-28^{\circ} \mathrm{C}$ increased the germination rate, but the low and high temperatures of $5,7,31,34$, and $35^{\circ} \mathrm{C}$ reduced the germination rate by increasing the cumulative hours under those conditions. In the next step, the relative effect weights of temperatures except $29^{\circ} \mathrm{C}$ on the germination rate were investigated by multiple regression analysis (Table 2). The standardized regression coefficient of each temperature indicates the relative weight of its effect on the germination rate. Based on the results, $19^{\circ} \mathrm{C}$ had the largest effect weight, and the farther away the temperature was from $19^{\circ} \mathrm{C}$, the smaller the effect weight became. Additionally, the standardized coefficient of each temperature was converted to a ratio relative to $19{ }^{\circ} \mathrm{C}$ and combined with the effect direction, i.e., whether the effect on the germination rate was positive or negative, which was derived by correlation analysis. 
Table 2. Correlation and multiple regression analyses between germination rates and the cumulative hours within the supplied temperatures. Correlation analysis was performed for all supplied temperatures. Temperatures confirmed to be not significant in the correlation analysis were not included in the multiple regression analysis. 'Impact weight ratio' was converted based on the largest absolute value of the standardized regression coefficients, specifically, that of $19^{\circ} \mathrm{C}$

\begin{tabular}{c|c|c|c}
\hline \multirow{2}{*}{$\begin{array}{c}\text { Temperature } \\
\left({ }^{\circ} \mathbf{C}\right)\end{array}$} & Correlation analysis & \multicolumn{2}{|c}{ Multiple regression analysis } \\
\cline { 2 - 4 } & Correlation coefficient & $\begin{array}{c}\text { Absolute value of the standardized } \\
\text { regression coefficient }\end{array}$ & $\begin{array}{c}\text { Impact weight } \\
\text { ratio }\end{array}$ \\
\hline 5 & $-0.106^{* * *}$ & $0.092^{* *}$ & -0.22 \\
7 & $-0.038^{* *}$ & $0.116^{* *}$ & -0.27 \\
10 & $0.043^{* *}$ & $0.190^{* *}$ & 0.45 \\
11 & $0.107^{* *}$ & $0.094^{* *}$ & 0.22 \\
13 & $0.103^{* *}$ & $0.245^{* *}$ & 0.58 \\
16 & $0.194^{* *}$ & $0.331^{* *}$ & 0.78 \\
17 & $0.473^{* *}$ & $0.416^{* *}$ & 0.99 \\
19 & $0.293^{* *}$ & $0.421^{* *}$ & 1.00 \\
22 & $0.258^{* *}$ & $0.390^{* *}$ & 0.92 \\
23 & $0.420^{* *}$ & $0.369^{* *}$ & 0.88 \\
25 & $0.124^{* *}$ & $0.265^{* *}$ & 0.63 \\
28 & $0.080^{* *}$ & $0.225^{* *}$ & 0.53 \\
29 & $-0.001^{\mathrm{ns}}$ & - & 0.00 \\
31 & $-0.053^{* *}$ & $0.101^{* *}$ & -0.24 \\
34 & $-0.079^{* *}$ & $0.077^{* *}$ & -0.18 \\
35 & $-0.156^{* *}$ & $0.137^{* *}$ & -0.32 \\
\hline
\end{tabular}

Nonlinear regression analysis of these converted values was performed to estimate the effect of temperature, including the non-supplied temperature, on the germination rate (Fig. 1). When the temperatures with a $0.1^{\circ} \mathrm{C}$ interval were substituted into the derived equation, the impact weight on germination was the highest for $18.9^{\circ} \mathrm{C}$ and declined gradually for increasingly distant temperatures. The impact weights of 8.0 and $29.7^{\circ} \mathrm{C}$ on germination were both 0.00 , which indicated that those temperatures had no influence on the germination rate, and their contiguous temperatures also had little influence. In addition, temperatures below $8.0{ }^{\circ} \mathrm{C}$ and above $29.7{ }^{\circ} \mathrm{C}$ negated the temperature accumulation for germination because they were given a negative germination impact weight. These relationships between temperature and germination were consistent with the results of the analysis of the actual supplied temperatures (shown in Table 2).

\section{Temperature requirement for vigorous germination based on the SSVT}

The temperature requirement for vigorous seed germination of $A$. senescens was calculated by linear regression analysis between the germination rate and TS (Fig. 2). The TS was the hourly accumulated 'impact weight on germination'. The temperature requirement of $A$. senescens was 294TS because the germination rate was above $85 \%$ when the TS was higher than 294. 


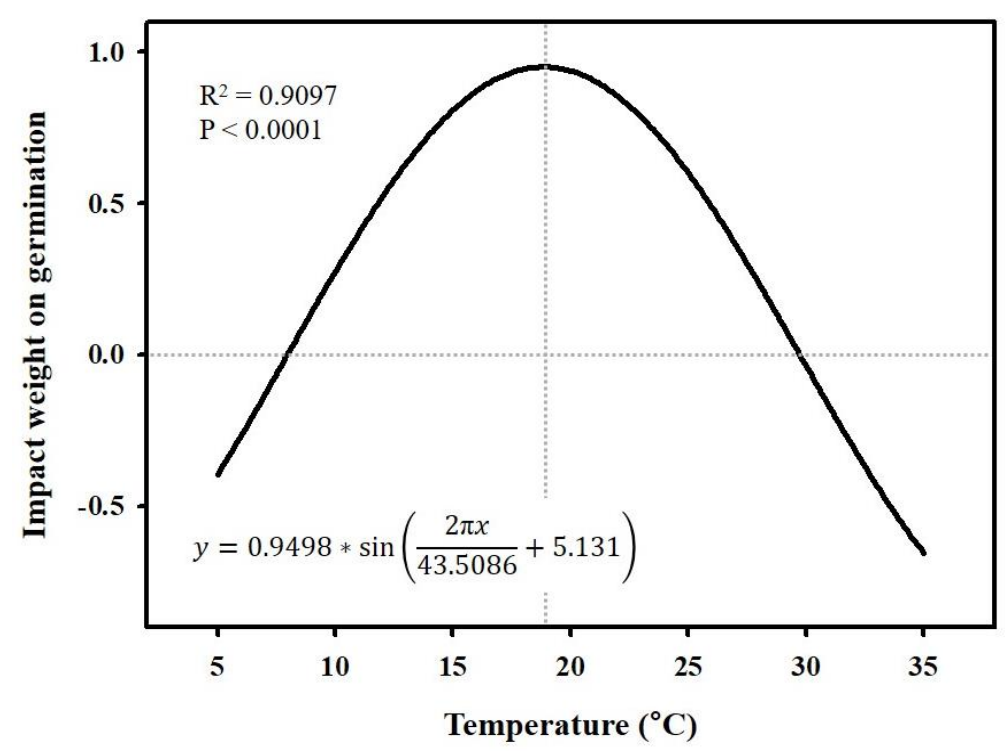

Figure 1. Regression curve of the impact weight on germination according to temperature. The curve was derived from the standardized regression coefficient ratios

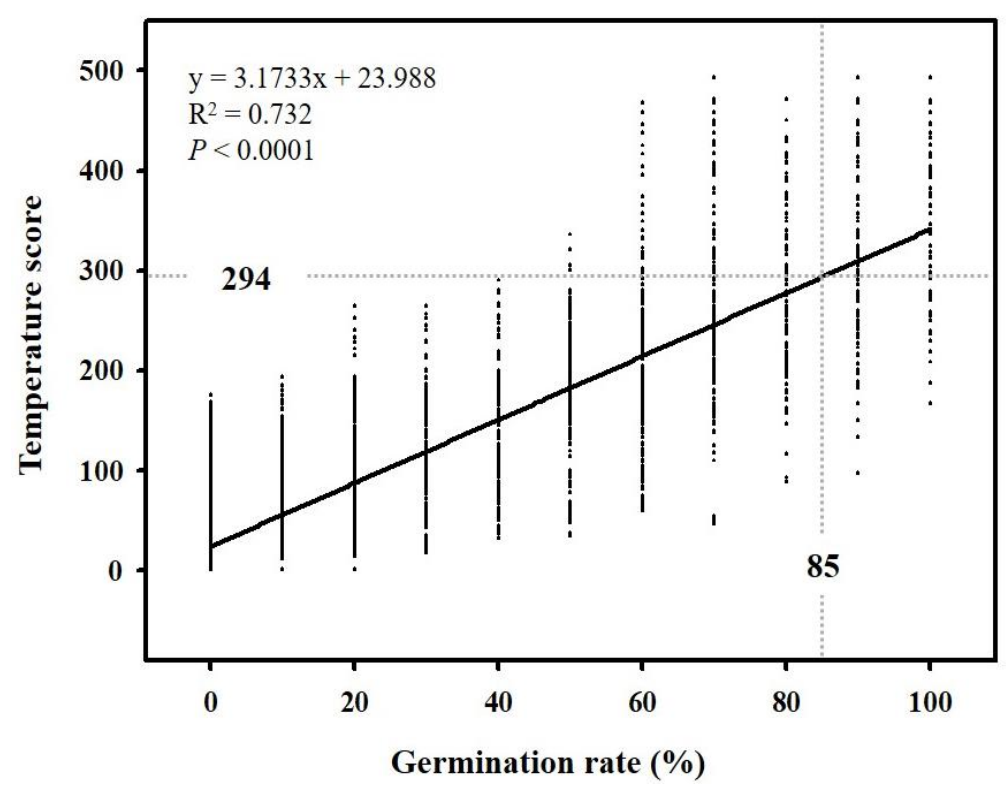

Figure 2. Linear regression analysis between the temperature score (TS) and germination rate. The TS is the accumulated value of the hourly temperature data according to the equation in

Figure 1. A germination rate of $85 \%$ was the criterion used to evaluate seed vitality, as suggested by the Royal Botanic Gardens, Kew (Newton et al., 2009)

\section{Verification and validation of the SSVT}

A new germination test was performed to assess the validity of 'impact weight on germination' and the SSVT equation. To this end, the time required to reach an $85 \%$ germination rate in each temperature treatment was investigated (Fig. 3A). Since a higher 'impact weight on germination' induced earlier fulfillment of the temperature requirement, the time to reach $85 \%$ germination exhibited a hump-shaped relationship 
with 'impact weight on germination'. Germination in the $20^{\circ} \mathrm{C}$ treatment, which was given the highest 'impact weight on germination', reached $85 \%$ at the earliest time, 15 DAS. The farther the temperature was from $20{ }^{\circ} \mathrm{C}$, the more delayed the time to reach $85 \%$ germination became (in inverse proportion to the 'impact weight on germination'). This pattern was especially pronounced in the 5,30 and $35^{\circ} \mathrm{C}$ treatments, which had negative 'impact weight on germination' values: the times to reach $85 \%$ germination were over 20 DAS and noticeably delayed compared to those of the other treatments. Thus, the 'impact weight on germination' metric and the equation established as part of the SSVT for comparing temperature treatments were effective.
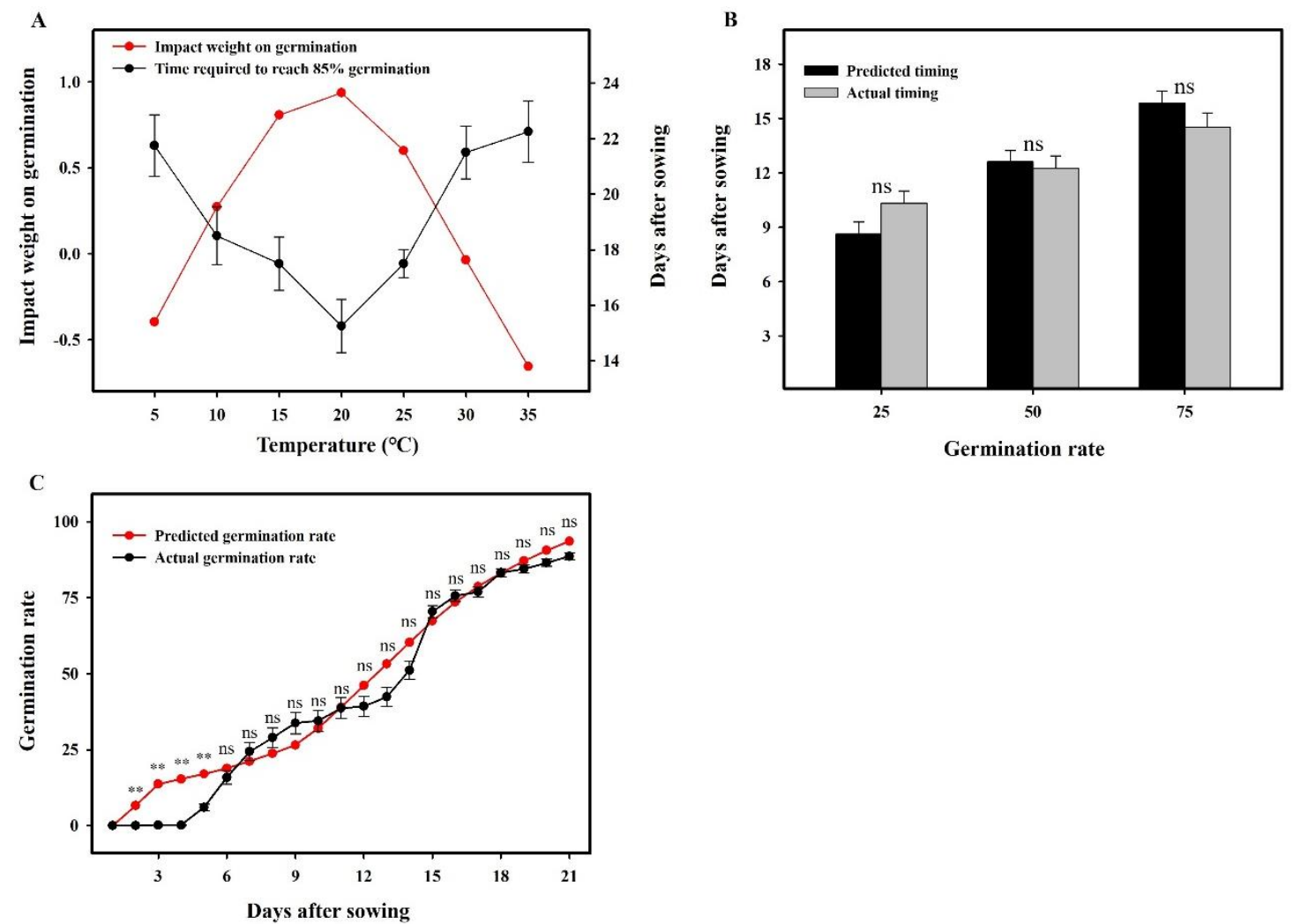

Figure 3. Verification and validation of the species-specific seed vigor test. (A) Impact weight on germination and the time required to reach $85 \%$ germination by temperature. In the germination test used for verification, temperatures on the $X$-axis were supplied to each treatment 3-9 days after sowing (DAS), and $20^{\circ} \mathrm{C}$ was supplied before 3 and after 9 DAS. (B) The predicted and actual times required to reach 25,50 and $75 \%$ germination. $(C)$ The predicted and actual germination rates with increasing DAS

The adequacy of these methods for predicting the germination rate was also tested, which included validation of whether the temperature requirement of $A$. senescens for vigorous seed germination was correctly calculated. The predicted times to reach 25,50 and $75 \%$ germination calculated by the regression between the TS and germination rate were compared to the actual measured times (Fig. 3B). The actual and predicted times to reach $25 \%$ germination were 10.3 and 8.6 DAS, respectively, differing by approximately 2 days. Discrepancies between the predicted and actual times were lowest at a $50 \%$ germination rate $(0.4$ days $)$ and $75 \%$ germination rate (approximately 
1 day). Consequently, the actual and predicted times to reach 25,50 and $75 \%$ germination rates exhibited no significant differences, even though the largest discrepancy between them was approximately 2 days.

The predicted and actual changes in the germination rate with the elapse of DAS were also compared (Fig. 3C). The predicted germination rates until 5 DAS were higher than the actual values because the predicted germination rates estimated by linear regression increased from the beginning, while actual germination did not start until 34 DAS. Overall, the predicted and actual germination rate changes over time did not differ, except during the period before 5 DAS, even though the actual values fluctuated compared to the stable predicted line. The mean value of the difference between the predicted and actual values over the whole period was $5.4 \%$, and the mean error after 6 DAS decreased to $4.2 \%$. Thus, prediction of the germination rate by the SSVT equation and the temperature requirement of $A$. senescens was reliable with no significant error.

\section{Regional adaptation under climate change}

The temperature requirement and SSVT equation of A. senescens were applied to hourly temperature data from Geumsan, Chungcheongnam-do, in the 2017-2018 season (Fig. 4). Seeds sown in late October 2017 did not receive sufficient temperature accumulation for germination, namely, a TS, until March 10 of the following year (a period of more than 4 months). Since the mean temperature during the period was $0.3{ }^{\circ} \mathrm{C}$, the nonaccumulation of the TS was likely due to the negating effect of the lowtemperature part of the SSVT equation. As a result, seeds sown in late October 2017 began to undergo temperature accumulation on March 10 of the following year. On April 30, 2018, the accumulated TS reached 294TS, which indicated the time of vigorous seed germination. These results supported the 'sowing in October and germination in spring of the following year' specification in the Korea Biodiversity Information System (Korea National Arboretum, 2019).

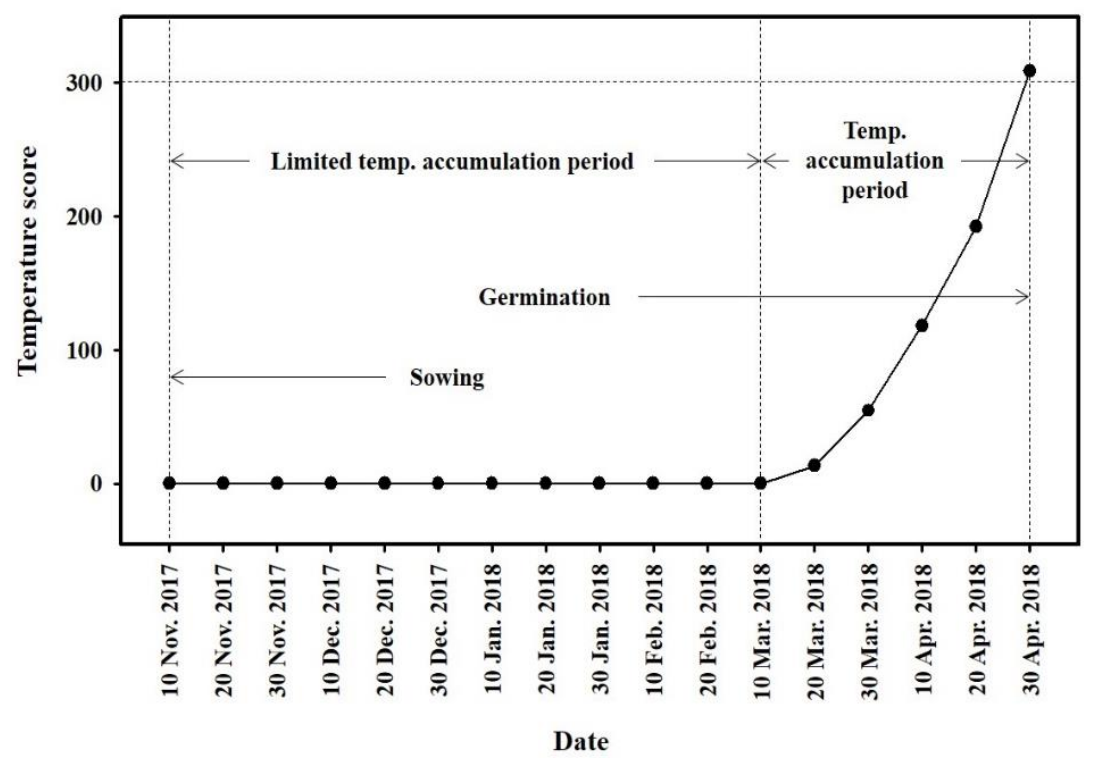

Figure 4. Temperature score accumulation patterns of Allium senescens L. seeds during the 2017-2018 season in Geumsan, Korea. It was assumed that seeds were sown in late October based on the Korea Biodiversity Information System (Korea National Arboretum, 2019) 
The effect of climate change was estimated by hourly temperature data collected from 1999-2018 (Table 3). The mean date of germination in 1999-2018 was May 3, and the earliest date was April 23. The more elevated the temperature was, the more the predicted date of germination advanced. If the temperature was elevated by $6.0^{\circ} \mathrm{C}$, the germination date was predicted to be more than one and a half months earlier than at present. Based on the predicted earliest date, that germination date would move forward much more rapidly. The germination date, which is April 23 at present, gradually advanced with elevated temperature until the temperature was elevated by $2.0^{\circ} \mathrm{C}$. If the temperature was elevated by $2.5^{\circ} \mathrm{C}$, the germination date was predicted to be markedly advanced to November 23. These results indicate that seeds sown in October would germinate within one month in the same year without going through winter if the temperature was elevated by $2.5^{\circ} \mathrm{C}$ or more.

Table 3. Predicted germination date of Allium senescens L. according to temperature elevation. The temperature elevations were applied to the hourly temperature data from Geumsan, Korea, collected in 1999-2018 by the method of Park et al. (2018)

\begin{tabular}{c|c|c}
\hline \multirow{2}{*}{$\begin{array}{c}\text { Temperature elevation } \\
\left({ }^{\circ} \mathbf{C}\right)\end{array}$} & \multicolumn{2}{|c}{ Predicted germination date } \\
\cline { 2 - 3 } 0.0 & Mean date & Earliest date \\
0.5 & $3 \mathrm{May} \pm 1.4$ & $23 \mathrm{Apr}$. \\
1.0 & $1 \mathrm{May} \pm 1.5$ & $21 \mathrm{Apr}$. \\
1.5 & $29 \mathrm{Apr} . \pm 1.5$ & $18 \mathrm{Apr}$. \\
2.0 & $27 \mathrm{Apr} . \pm 1.5$ & $16 \mathrm{Apr}$. \\
2.5 & $24 \mathrm{Apr} . \pm 1.5$ & $14 \mathrm{Apr}$. \\
3.0 & $14 \mathrm{Apr} . \pm 8.1$ & $23 \mathrm{Nov}$. \\
3.5 & $12 \mathrm{Apr} . \pm 8.0$ & $21 \mathrm{Nov}$. \\
4.0 & $1 \mathrm{Apr} . \pm 10.9$ & $19 \mathrm{Nov}$. \\
4.5 & $30 \mathrm{Mar} . \pm 10.7$ & $19 \mathrm{Nov}$. \\
5.0 & $28 \mathrm{Mar} . \pm 10.6$ & $18 \mathrm{Nov}$. \\
5.5 & $26 \mathrm{Mar} . \pm 10.5$ & $18 \mathrm{Nov}$. \\
6.0 & 17 Mar. \pm 12.0 & $17 \mathrm{Nov}$. \\
\end{tabular}

\section{Discussion}

Temperature is a dominant factor among the diverse environmental factors that affect the rate and velocity of germination (Bellairs and Bell, 1990; Cony and Trione, 1996). Since the rate and velocity of germination vary among not only species but also genotypes of the same species, many studies investigating the effect of temperature on germination have been performed on individual species or genotypes (Acharya et al., 1983). For example, in rapeseed (Brassica napus L.), cold-resistant varieties maintained high germination rates under low-temperature conditions, but the germination rates of cold-sensitive varieties were markedly reduced (Luo et al., 2018).

Base temperature $\left(T_{b}\right)$ is an important factor in the relationship between seed germination and temperature. $T_{b}$ is the lowest temperature threshold affecting seed germination, and the process of germination is controlled by the accumulation of temperature above $T_{b}$ (Batlla and Benech-Arnold, 2015). Various models have been developed to investigate $T_{b}$ (Dahal et al., 1990; Steinmaus et al., 2000; Tan et al., 2017), 
and $T_{b}$ can be set differently because calculation methods differ among models (Luo et al., 2018). These results suggest that the selection of a suitable model is required and that model fitting for the target species must be performed. The process examined in this study might be another useful method for investigating $T_{b}$. In the present study, the temperature corresponding to $T_{b}$ was $8.0^{\circ} \mathrm{C}$, and germination was accelerated by the accumulation of temperature above $8.0{ }^{\circ} \mathrm{C}$. In contrast, temperatures above $30{ }^{\circ} \mathrm{C}$ did not accelerate germination, which suggested that another $T_{b}$, representing the highest temperature threshold, was also required. The investigation of the upper and lower limits of $T_{b}$ would enable the selection of effective temperatures for germination, which could be set to $8-30{ }^{\circ} \mathrm{C}$.

The investigation of temperatures below $T_{b}$ is also important. Seed germination is an essential stage that affects the maintenance of populations and regional adaptation for ecological restoration (Qiu et al., 2010). In actual field conditions, temperatures below $T_{b}$ are common, in contrast to the constant or stable temperatures above $T_{b}$ that are supplied in growth chambers. If $T_{b}$ is applied at a lower threshold, then the temperatures below $T_{b}$ are meaningless. In this study, in contrast, temperatures below $T_{b}$ negated the effect of temperature accumulation on germination. These negating effects on temperature accumulation could be utilized during seed storage. When the accumulation of effective temperature leads to germination activation, the negating effect on temperature accumulation could be used to reverse the activated state back to the stable state. Many studies have reported that low temperatures limit the metabolic processes required for germination by controlling lipid and protein mobilization and enzyme activities (Nykiforuk and Johnson-Flanagan, 1994; Hoppe and Theimer, 1997).

In addition, the existence of optimal conditions for the acceleration of germination suggested that changes in the germination rate and velocity vary among temperature levels, even in the effective range (Luo et al., 2018). This variability in germination behavior among temperatures suggests that the timing of sowing must be flexible to accommodate the thermal conditions of the target area (King et al., 1986; Russo et al., 2010). In other words, the effect of ecological restoration could be maximized by sowing seeds at the optimal time, thereby minimizing the number of days to germination. The tool predicting germination in this study was 'temperature requirement', which was expressed as the TS. The TS represented the influence of a temperature regime on germination, and the 'temperature requirement' was the hourly accumulated value of the TS to a specific criterion. In this study, the TS accumulation criterion was $85 \%$, which was chosen to add vigorous germination information to the seed storage DB. However, the germination rate criterion can be adjusted to calculate the temperature requirement. The objectives of this study were somewhat contradictory: to determine how to stabilize seeds for long-term storage and how to activate germination for restoration when needed.

Seed vigor information is only a small part of the seed storage DB, which includes diverse information, such as the weight and size of seeds, collection site and timing, and donating country or institution. Thus, we tried to input information that was simple but useful and diverse into the seed storage DB. The 'impact weight on germination' equation and 'temperature requirement' derived by the SSVT were entered into only two boxes in a small section of the seed storage DB. However, these conditions provide various types of information, such as the optimal and effective temperature ranges accelerating germination, the conditions that negate effective temperature accumulation and the time required to reach the ideal germination rate. Furthermore, this 
formularization and quantification of the relationship between germination and temperature can be utilized in various ways. The estimation of the climate change effect performed in this study is only one example. Preferentially, ecosystem destruction and extinction should no longer occur. We anticipate that the results of this study on germination temperature and climate change effect estimation will be utilized as fundamental information in the preparation of stored seeds for restoration.

\section{Conclusion}

In this study, the effective or positive temperature range for germination of $A$. senescens was set, and the impact weight on germination by temperature levels was evaluated. Furthermore, the temperatures that negated the temperature accumulation for germination were verified. Since the SSVT equation was compared to the actual temperature data in the field, it was possible to predict the changes in germination timing. In general, temperate plants need to accumulate low-temperature effects to break their dormancy, and germination would begin only under this condition. Concretely, it was reported that seeds of A. senescens need a chilling period longer than $427 \mathrm{~h}$ at temperatures below $5{ }^{\circ} \mathrm{C}$ (Suh et al., 2005). Thus, it could be regarded that the changes in germination timing resulting from increased temperatures would occur for only the stored seeds in the low temperature range, as observed in this study. Self-sown seeds in the field may be more seriously affected by climate change than the seeds stored at low temperatures during certain periods. The period for vernalization by lowtemperature accumulation required for dormancy release would be shortened due to the elevated temperature. If the chilling requirements of $A$. senescens are not fulfilled, the germination of seeds would become virtually impossible. These facts suggest that both temperature conditions for vernalization and germination must be considered together to more precisely predict the effects of climate change. In fact, the results of studies that examined both the chilling required for dormancy release and the temperature accumulation to germination are being reported on not only the seeds but also the buds of temperate plants (Park and Park, 2019).

Meanwhile, this study had modeling limitations that were aimed at seed storage and ecological restoration at the same time. If seed storage is then aim, further studies on actual storage conditions below $5{ }^{\circ} \mathrm{C}$, which were examined in this study, should be performed. In contrast, if the final objective is ecological restoration, detailed habitat conditions such as soil characteristics and incline direction should also be considered.

Acknowledgements. We are very grateful to the Chungcheongnam-do Forest Environment Research Institute for providing seeds. This work was supported by a National Research Foundation of Korea (NRF) grant funded by the Korean government (MSIT) (No. NRF-2017R1D1A1B03034615).

\section{REFERENCES}

[1] Acharya, S. N., Dueck, J., Downey, R. K. (1983): Selection and heritability studies on canola/rapeseed for low temperature germination. - Canadian Journal of Plant Science 63(2): 377-84.

[2] Batlla, D., Benech-Arnold, R. L. (2015): A framework for the interpretation of temperature effects on dormancy and germination in seed populations showing dormancy. - Seed Science Research 25(2): 147-158. 
[3] Bellairs, S., Bell, D. T. (1990): Temperature effects on the seed-germination of 10 Kwongan species from Eneabba, Western-Australia. - Australian Journal of Botany 38(5): 451-458.

[4] Broadhurst, L. M., Jones, T. A., Smith, F. S., North, T., Guja, L. (2015): Maximizing seed resources for restoration in an uncertain future. - BioScience 66(1): 73-79.

[5] Choi, H.-Y., Kim, G.-H. (2014): Inhibitory effects of Allium senescens L. methanol extracts on reactive oxygen species production and lipid accumulation during differentiation in 3T3-L1 cells. - Korean Journal of Food Science and Technology 46(4): 498-504.

[6] Chung, M.-S. (2010): Volatile compounds of the cultivated dumebuchu (Allium senescens L. var. senescens). - Food Science and Biotechnology 19(6): 1679-1682.

[7] Chung, M. S., Lee, M. S. (2001): Chemical composition and texture of Allium senescens. - Journal of the Korean Society of Food Science 17: 60-64.

[8] Cony, M., Trione, S. O. (1996): Germination with respect to temperature of two Argentinian Prosopis species. - Journal of Arid Environments 33: 225-236.

[9] Dahal, P., Bradford, K. J., Jones, R. A. (1990): Effects of priming and endosperm integrity on seed germination rates of tomato genotypes: I. Germination at suboptimal temperature. - Journal of Experimental Botany 41(11): 1431-1439.

[10] Hoppe, A., Theimer, R. R. (1997): Degradation of oil bodies isolated from cotyledons during germination of rapeseed seedlings. - Journal of Plant Physiology 151(4): 471-478.

[11] King, J. R., Kondra, Z. P., Thiagarajah, M. R. (1986): Selection for fast germination in rapeseed (Brassica napus L. and B. campestris L.). - Euphytica 35(3): 835-842.

[12] Korea National Arboretum (1997): Illustrated Rare and Endangered Species in Korea. Korea National Arboretum, Seoul, Korea.

[13] Korea National Arboretum (2019): Korea Biodiversity Information System. http://www.nature.go.kr/kbi/plant/pilbk/selectPlantPilbkDtl.do.

[14] Luo, T., Xian, M., Khan, M. N., Hu, L., Xu, Z. (2018): Estimation of base temperature for germination of rapeseed (Brassica napus) using different models. - International Journal of Agriculture and Biology 20(03): 524-530.

[15] Marcos-Filho, J. (2015): Seed vigor testing: an overview of the past, present and future perspective. - Scientia Agricola 72: 363-374.

[16] Newton, R., Hay, F., Probert, R. (2009): Protocol for Comparative Seed Longevity Testing. Technical Information Sheet 01. - Royal Botanic Gardens, Kew, London.

[17] Nykiforuk, C. L., Johnson-Flanagan, A. M. (1994): Germination and early seedling development under low temperature in Canola. - Crop Science 34(4): 1047-1054.

[18] Oh, M., Bae, S.-Y., Chung, M.-S. (2012): Volatile compounds of essential oils from Allium senescens L. var. senescens. - Korean Journal of Food and Cookery Science 28(2): 143-148.

[19] Park, Y., Park, H.-S. (2019): Heat unit model for classifying the environmentally controlled period during ecodormancy. - Scientia Horticulturae 25: 6108536.

[20] Park, Y., Lee, B., Park, H.-S. (2018): Predicted effects of climate change on winter chill accumulation by temperate trees in South Korea. - The Horticulture Journal 87(2): 166173.

[21] Qiu, J., Bai, Y., Fu, Y.-B., Wilmshurst, J. F. (2010): Spatial variation in temperature thresholds during seed germination of remnant Festuca hallii populations across the Canadian prairie. - Environmental and Experimental Botany 67(3): 479-486.

[22] Russo, V. M., Bruton, B. D., Sams, C. E. (2010): Classification of temperature response in germination of Brassicas. - Industrial Crops and Products 31(1): 48-51.

[23] Steinmaus, S. J., Prather, T. S., Holt, J. S. (2000): Estimation of base temperatures for nine weed species. - Journal of Experimental Botany 51(343): 275-286.

[24] Suh, J.-T., Hong, S.-Y., Yoo, D.-L., Ryu, S.-Y., Song, J.-S. (2005): Low temperature requirement hour for dormancy breaking of wild flowers in Highland, Allium senescens 
Lychnis cognata and Sedum kamtschaticum. - Journal of the Korean Institute of Interior Landscape Architecture 7(1): 95-103.

[25] Tan, M., Liao, F., Hou, L., Wang, J., Wei, L., Jian, H., Xu, X., Li, J., Liu, L. (2017): Genome-wide association analysis of seed germination percentage and germination index in Brassica napus L. under salt and drought stresses. - Euphytica 21: 340.

[26] van der Valk, A. G., Bremholm, T. L., Gordon, E. (1999): The restoration of sedge meadows: seed viability, seed germination requirements, and seedling growth of Carex species. - Wetlands 19(4): 756-764. 